\title{
Growing Importance of Distance Education
}

\author{
Milena Bogdanović \\ University of Niš, Teacher Training Faculty, Partizanska 14, Vranje, Serbia \\ Email: mb2001969@beotel.net, milenab@ucfak.ni.ac.rs
}

\begin{abstract}
Distance education can be very effective use of instructional materials with visual, auditory, audiovisual and multimedia content. Visual content can be in the form of text, drawings, pictures, graphics and models, and the like. Auditory facilities are oral presentation or a speech, musical accompaniment, different sounds, etc.. Audiovisual content combine visual and auditory content, usually in the form of television shows, films or videos. Multimedia, combining text, images, sound, animation and video, and playing them before they used very different means, although in recent times for playing multimedia files commonly used multimedia computer, a data storage CD-ROM or the Internet. Using multimedia is extremely important in distance education as a lecturer is usually not physically present with the participants to draw their attention, motivate them to learn and explain the content that students are having difficulty understanding.
\end{abstract}

Index Terms - Multimedia, Internet, Distance Education, E-Learning, Information and Communication Technology.

\section{INTRODUCTION}

The beginning of the new millennium is a very dynamic period in the development of computer science and technology. Digital world is becoming daily life support, but also it's the basic factor in the globalization of the world. Computers, on the one hand, integration into modern culture, on the other hand can be recognized as a leading force in the growth of world economy. New technologies are being introduced continuously, and thereby become obsolete almost as soon as they occur.

On the other hand, the rapid development of computer discipline has substantial effects on education, both at the educational content and methods of education. Thus, for example, networking and Web become a critical foundation of computer science, and simultaneously one of the basic pedagogical resources, uslovaljavajući changes in the educational process, not only in computer science but also in other areas. Progress made in multimedia technology at the level of personal computers, as well as in networking technology and especially internet and web, created new opportunities to transform the teaching process and the educational systems of significant scale, especially in the developed world and in Serbia [1]. The teacher's role in this process changes but remains crucial: although globalization of information technology allows students to visit faraway museums, to make electronic excursions to faraway archaeological sites and communicate via video conference, the school is that students need to learn critical thinking, social behavior, work performance, personal responsibility, which introduces them to the models and mentors, develops and supports curiosity.

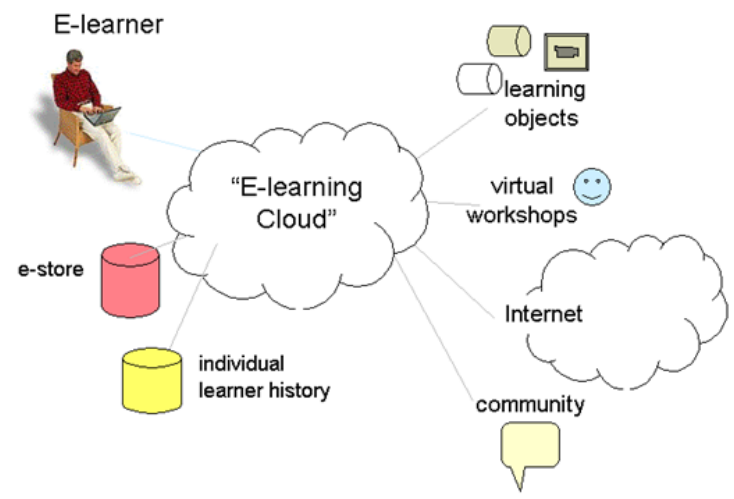

Figure 1. E-learning 


\section{TECHNOLOGY}

Today, distance education can hardly be imagined without the significant use of ICT [2]. However, a number of different software can create a negative initial attitudes toward distance education on both sides, so that potential teachers / instructors, and students in online classes. lecturer / instructor should be familiar with all types of software (software ) to be used in teaching. For successful implementation of specific teaching methods in distance education using appropriate technology needs to teacher / instructor for each software is available for use instructions. It is recommended that at least one and preferably several times, carry out training for the practical use of all types of software needed to perform elements of the on-line teaching as provided in the scenario of a learning process.
The next important component of a quality technical support (requires hardware, software and support staff) to be the teacher / instructor facilitate setting up of educational content on-line (eg, recording audio / video, digitization of data, conversion into the chosen format, etc..), And customize the configuration appropriate software, technical problems utklanjanje taking into account the used hardware (hardware, computer networks) and software. Technical support should be organized for students to easily become involved in different types of technology supported activities in distance education. Students should be directed to the method of installation and use them tehologija intended to enable them to use on-line educational materials and a variety of communication activities.

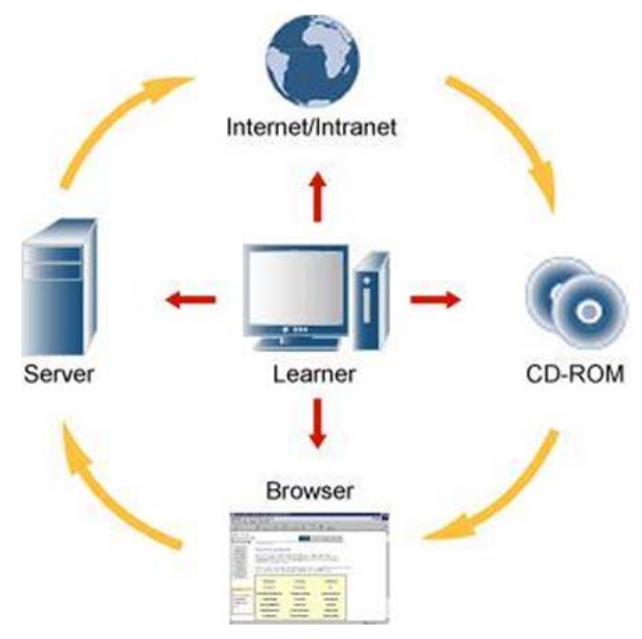

Figure 2. ICT and distance education

Successful operation of technical support is based on a defined plan of action. The action plan should include answers to questions such as:

- How will the students to obtain and install the software needed for the course?

- Who needs to give users answers to the questions related to technical support?

- How students can identify specific problems and that can act in accordance with certain problems?
- What is the technical support phone number in case of need for immediate help in solving the problem of users?

- What is the expected time of reporting the problem to its resolution or receipt of information on alternative treatment?

Using a single LMS provides the following set of requirements for hardware and software required for teachers / instructors and students as users of the system, followed by setting their settings in order to have access to adequate resources LMS. 


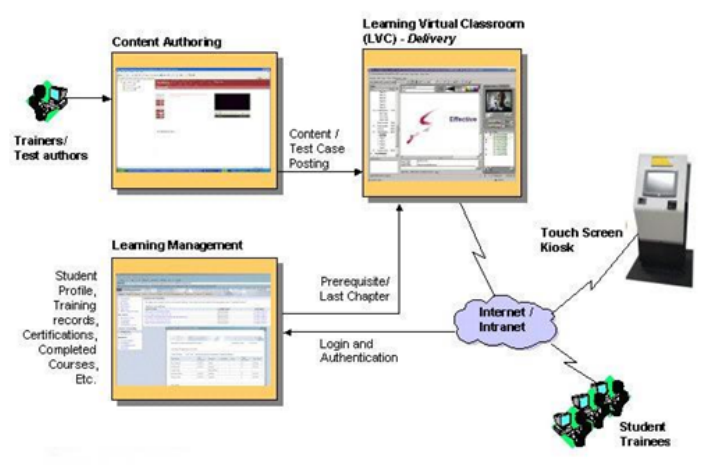

Figure 3. Trainers/ Test authors and Student Trainees

All participants should be familiar with the minimum requirements for the basic computer configuration that allows them to correctly use the LMS (connection to the Internet, the technical characteristics of their computer: processor, working memory, disk space, monitor, etc..) And the necessary audiovisual equipment (speakers, sound cards, camera and microphone for videoconferencing and the like.). When the necessary software to be installed on the operating system (Windows, Linux, etc..), Browser (product, version, various inserts - plugins), a program for working with e-mail program to work with network news and the rest of the program-specific equipment.

Adjusting the settings is particularly important because it wrongly entered values can disable the use of substitute parts or equipment, however, the LMS system as a whole. The main part of the settings related to screen size (eg $800 * 600 * 768$ or 1024$)$, color depth, font size, etc.. The next section applies the settings on your browser which allows the execution of Java programs (applets), execute ActiveX controls, entering local data - cookies, access outside the local network (security wall - firewall, proxy), and the like.

Carefully prepared instructions for installing additional software required for distance education will facilitate the process of technical preparations for users with less skill in working with information technology. It is important that the installation instructions contain the appearance of the user display with emphasis on enrollment data / parameters, and each carried a step.

For the successful utilization of the pedagogical elements and methods of working with students in distance education it is important that the users in the forefront of educational content, and not having problems with technology. Appropriate technical equipment and computer literacy are essential prerequisites for a successful user participation in distance education. In addition to ensuring the necessary forms of technical support for users, we recommend evaluation of their technical equipment and knowledge of information technology prior to on-line education and to provide additional technical training or instruction for students who might have difficulty in mastering the use of educational technology.

Only oral presentation and presentation of educational content in the form of text usually causes information overload or problems related to attracting and keeping the attention of the instruction participants. Receiving information, only one communication channel makes it difficult to create associations and connect new information with previous knowledge and experiences. However, if information is presented as a combination of text, sound and image, it significantly increases the attraction of attention and deepens the experiences of the participants and creates a greater possibility of creating associations between different representations of certain information. However, it is necessary to take into account the principles of effective use of multimedia elements such as images and animations [3].

Using multimedia is extremely important in distance education as a lecturer is usually not physically present with the participants to draw their attention, motivate them to learn and explain the content that students are having difficulty understanding.

The positive effects of multimedia are:

$\checkmark \quad$ attracting participants' attention;

$\checkmark$ greater level of interest, motivation and satisfaction of participants;

$\checkmark \quad$ a better understanding of content and efficient learning of new concepts;

$\checkmark$ better memory content and the ability to apply knowledge in new situations.

Application of multimedia on the web requires knowledge about the development and appropriate use of audio, video and animation, and advanced multimedia development tools on the web. In general the higher the level of multimedia, the greater the possibility of attracting the attention of participants, a higher level of vividness, clarity and understanding instructions, and practical applicability of acquired 
knowledge. To illustrate the use of multimedia applications can be used for example on-line course on the assembly of computers. This course can be designed only in text form with detailed instructions for each step and a verbal description of the components. Another way to design the course with the use of text instructions and images for specific steps in the preparation. The third way is to use text, images and recorded verbal instructions by the instructor. The fourth way is to use text and video of some steps in the assembly of computers and connecting components. The fourth method is to use text and video depicting the various steps and audio recordings of oral instructions by the instructor [4].

\section{III.WHAT ARE THE ELEMENTS OF MULTIMEDIA?}

Multimedia elements are the various forms of media mono records. They have their place in many areas of computer application. From the web site software packages designed for play and learning of preschool children.

Creating content with multimedia elements should mean more than a series of colorful images and a variety of audio and video effects. It is necessary to enable the user to easily navigate the material. In addition to better and more efficient way of presenting content, multimedia elements must be able to effectively search for and extract those that relate to the user's upit.Kod writing educational materials that contain multimedia elements used to design different organization than that of conventional paper documents. It is not only possible to copy (copy-paste) a word file for printing on paper, exported to HTML, add a few tags and to call the on-line educational material. It takes from start to write educational materials so you can best take advantage of media opportunities. Multimedia educational materials need to take advantage of all multimedia capabilities in a way to use multimedia elements.

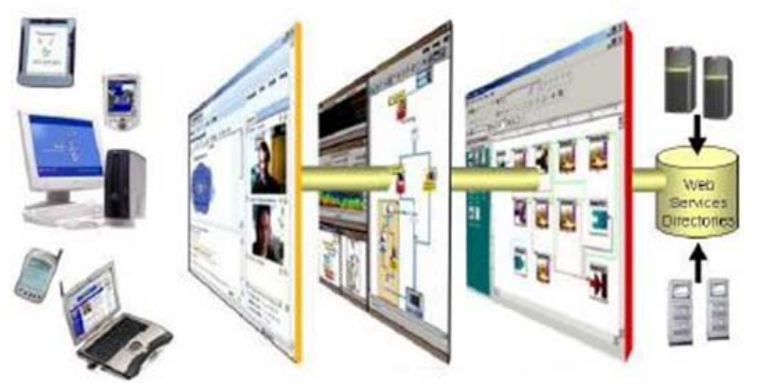

Figure 4. E-Learning's and Distance Leaning tools

If the majority of the teaching done in the traditional manner in the classroom or lab, and use of materials on the web is just a supplement to such teaching, is usually not necessary to create a complex system for on-line training because most of the educational content gets in the classical education and the printed literature, a consultation with a tutor / instructor may be in personal contact, ie. face to face.

However, if students mainly access educational content on-line and are rarely in direct contact face to face with the instructor, it is usually necessary to make a lot of effort and resources to design systems that will be easy to use and reasonably Users fill the need for social contact with the lecturer / instructor and other students.

\section{IV.TEACHING METHODS AND TECHNOLOGIES IN E-EDUCATION}

The application of certain methods in e-learning in a very large extent depends on the available technology. For example, if students can use a broadband Internet connection faster than $100 \mathrm{kbits}$ per second or more (broadband), a lecturer / instructor can record lectures and has available the appropriate server memory capacity and speed of Internet access, the educational content can be stored in the form of video lectures [6].

On the other hand, if users access educational content via a slower dial-up connection or if the server is available to the teacher / instructor with limited memory capacity of a weak connection to the Internet, most of the educational content is probably the best prepared in the form of written text and static visual illustrations that do not take up much memory space.

Particularly useful to consider various alternative solutions for complex systems to manage the educational process / content (Learning Management System - LMS, learning content management system LCMS). Such systems are usually integrated set of content on the web, testing, forums and communicate 
with users. However, if the teacher / instructor should only set exercises or tests and maintain a web forum on the web, it is useful to consider alternative solutions [5]. For example, in forums and discussion groups can use the services of popular portals such as Yahoo, and for making on-line exercises and tests is available free software such as Hot Potatoes.

\section{BOOKS ON E-EDUCATION}

1. Bates, AW (2004): Managing technological change: Strategies for leaders in higher education. CARNet, Zagreb. (181 pages) A rather detailed review and development strategy for managing e-education at universities and colleges. It is necessary to understand the context in which it develops products and services of e-education. Useful to managers in e-education and authors of online courses or course.

2. Rosenberg, MJ (2001): E-learning: Strategies for delivering knowledge in the digital age. McGraw-Hill, New York. (343 pages)

Detailed analysis of the role and possibilities of e-learning in business organizations. It contains practical examples. Very useful for the management of continuing education in corporations.

3. Picciano, AG (2001): Distance Learning: Making Connections Across Virtual Space and Time, Prentice Hall, Upper Saddle River, New Jersey. (253 pages) Overview of the area of distance education in respect of different technologies and media, educational institutions, teachers and students. The comprehensive view of the broader context of distance education that allows for the e-learning in the perspective of other analogous forms of education. Good for general information on distance education, and useful to managers in e-education.

4. Melton, RF (2002): Planning and developing open and distance learning: A quality assurance approach. RoutledgeFalmer, London. (223 pages) A detailed overview of the different elements that contribute to the quality of the course or courses for distance education. Very appropriate for an academic institution, the managers of distance education and authors of on-line courses or course.

5. McVay Lynch, M. (2002): The Online Educator: A Guide to Creating the Virtual Classroom, RoutledgeFalmer, London. (170 pages)

Overview of different technologies, forms of communication, techniques, strategies and pedagogical principles in e-learning. Succinct reminder of the many important factors in shaping the success of on-line courses or courses in e-learning. It is necessary for authors, instructors and managers of on-line courses or course.

6. Salmon, G. (2000): E-Moderating: The Key to Teaching and Learning Online, Kogan Page, London. (180 pages) Is often cited work on moderating on-line communication, ie. the interaction in relation to tasks and conduct dialogue and discussion with students in teaching e-learning. Contains recognized theoretical model of e-moderating, and numerous examples of situations with concrete messages exchanged between the moderator and the participants on-line teaching. Very useful for the development of competences in moderating online interactions.

7. Palloff RM, Pratt, K. (1999): Building learning communities in cyberspace: Effective strategies for the online classroom. JosseyBass, San Francisco. (206 pages) Collection of numerous guidelines and examples for successfully organizing and managing groups in e-education, and for more effective communication in individual and group interactions with students. Useful for trainers, mentors and moderators in online teaching.

8. Collison, G., Elbaum, B., Haavind, S., Tinker, R. (2000): Facilitating online learning: Effective strategies for moderators. Atwood Publishing, Madison. (216 pages) Overview of the role (moderator, initiator), dialog techniques and strategies to interact with the users e-education. Especially useful for better understanding and management of on-line dialogue.

9. Horton, W. (2000): Designing Web-based training: How to teach anyone anything anywhere anytime. Wiley, New York. (607 pages)

A lot of useful tips and examples with images from various on-line courses. Simple and understandable written and very comprehensive guide that step-by-step leads to a successful design and management course or courses in e-learning. Very useful for authors and designers of on-line courses or courses.

10. Hanna, DE, Glowacki-Dudka, M., Conceição-Runlee, S. (2000): 147 practical tips for teaching online groups: Essentials of Web-based education. Atwood Publishing, Madison. (74 pages) A collection of tips on on-line teaching for those who already know something about the area. It can serve as a reminder for designers 
and instructors of courses and courses in elearning.

11. Gilbert, SD (2001): How to be a successful online student. McGraw-Hill, New York. (267 pages)

View the many factors that influence the success of e-education students, the selfassessment of personal needs and abilities, to apply to attend the on-line courses or course, of obligations and execution of successful participation in on-line interaction with other students. Designed for e-learners.

12. Adams, T., Clark, N. (2001): The Internet: Effective online communication. Harcourt, Fort Worth. (368 pages) Basic communication technologies and services on the Internet, as well as tips for successful personal, group and public communication using electronic mail, network news, discussion groups, electronic conferences, web pages, multimedia content on the web, etc.. Useful for authors of online content, instructors and moderators, and participants in e-education, which are not sufficiently familiar with the basics of Internet communication.

\section{VI.CONCLUSION}

The more you use the latest technology in distance education, the less likely that computers and operating systems available to users allow their use. With the introduction of new technology should be "moderately conservative" or "moderately innovative" and focus on what's available to everyone, or most, especially when new technologies require significant investment or adjustment of students on-line education [7]. In addition, the education is at the forefront of technology, but the educational process and educational goals related to the specific topic area, and technology should not divert attention from these more important things to difficulties in its application or nonfunctional effects of the technology can achieve. Finally, the use of technology should be cost-effective, ie. trainer / instructor and designer of on-line content should always strive to objectively evaluate how the expensive technology that they want to apply (and to impose the students) more effective ways in which education of the well-organized and illustrated books of similar education content.

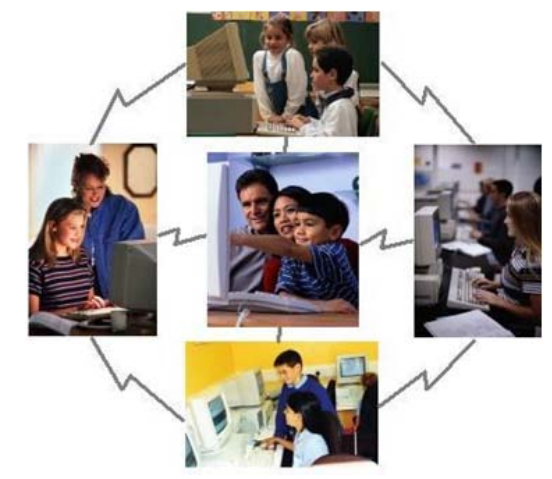

Figure 5. Life Long Learning

\section{REFERENCES}

[1] M. Bogdanović, „Educational Software, EDUCATION AND NATIONAL EDUCATION“, the Proceedings: The ability of national education in the globalization, p. 265-282, Teacher Training Faculty, Vranje, 2010. ISNBN 978-86-82695-71-4, COBISS.SR-ID 176593932

[2] M. Bogdanović, „Multimedia and Education features and options application", International Conference on Information Technology and Development of Education ITRO2011 Proceedings, pp. 308-311, University of Novi Sad, Technical faculty „Mihajlo Pupin”, Zrenjanin, Republic of Serbia, Zrenjanin, July 2011. ISBN: 978-86-7672-134-4
[3] Computing Curricula 2001, Chapter 3: Changes in the Computer Science Discipline, http://www.acm.org/education/

[4] B. Craig, „New Directions of ICT-Use in Education", http://www.unesco.org/education/educprog/lwf/dl/e dict.pdf.

[5] B. J. David, Writing Space: Computers, Hypertext, and the Remediation of Print, Second Edition. Mahwah: Lawrence Erlbaum Associates, 2001.

[6] C. Fallon, S. Brown, e-Learning Standards, CRCpress, 2003.

[7] O.K.Valery, M.K. Volodymir, P.S. Olexanndr, Distance Learning, Lifelong Learning in Europe 2, pp. 114-119, 2002. 
Milena Bogdanović is the assistant professor at the Theacher Training Faculty in Vranje, Serbia (major in Mathematics and Informatics - Mathematics 1, Mathematics 2, Elementary mathematical concepts, IT in Education, Educational technology, Elements of mathematics). She is the Reviewer of international journals - IJACSA - International Journal of Advanced Computer Science and Applications; Member of the editorial boards of international journals - International Journal of Computer Systems and Applications Inernational Scientific Press; Reviewer of the Book of solved tasks in Mathematics 2; Experience in teaching in secondary school and university; Participant in numerous seminars and training for eduational reform, active learning, Lifelong Learning, Mathematics and Applications. She is the author of two books and of about 40 of published scientific papers in the field of the mathematics and computer science. Her professional papers discuss problems in the field of applications of multimedia in teaching, combinatorial optimization, genetic algorithms, directable automata. 